Nigerian Journal of Physiological Sciences 24 (1): 63 -66 @Physiological Society of Nigeria, 2009

Available online/abstracted at http://www.bioline.org.br/np; www.ajol.info/journals.njps; www.cas.org

\title{
STUDENTS PERFORMANCE AND PERCEPTION OF NEUROPHYSIOLOGY: FEEDBACK FOR INNOVATIVE CURRICULAR REFORM IN A NIGERIAN MEDICAL SCHOOL
}

\author{
ED NWOBODO ${ }^{*}$, U. B. ANYAEHIE ${ }^{2}$, N. NWOBODO ${ }^{1}$, C. AWIWA $^{3}$, E. OFOEGBU ${ }^{2}$, \\ C. OKONKWO, C. ALIGEKWE AND B. BURDICK ${ }^{4}$ \\ 1. Faculty of Medicine, Nnamdi Azikiwe University at Nnewi. Nigeria, 2. College of Medicine, University of \\ Nigeria, Enugu Campus. Nigeria, 3. Faculty of Medicine, University of Benin, Benin City. Nigeria. 4. FAIMER \\ Institute, Market Road Philadelphia, USA. E-mail: ednwobodo@yahoo.com
}

\begin{abstract}
Summary: This study aimed at ascertaining the status of students' performances and their perception of the learning of neurophysiology in a Nigerian medical school. The goal of the study was to determine ways of addressing identified negative perceptions for the purpose of improving upon the overall learning and use neurophysiology knowledge by structured curricular reform. We analyzed and compared the performances of students in three areas of physiology at the second professional examinations over a three-year period $(n=300)$. We also surveyed learning experience of a batch of graduating doctors in neurosciences $(n=50)$ and surveyed the staff and students' perception of the teaching of neurophysiology. The students performances in neurophysiology was comparatively poorer than in cardiovascular and endocrinology aspects of the subject over a three year period at the second professional examinations. The reported students perception of their neurophysiology learning included uninteresting, abstract concepts, lack of real examples and conflicting facts with their prior basic knowledge. Over $50 \%$ of the graduands rated their learning experiences as poor or very poor or below average for the neuroscience courses. The analyses of the curricular contents of neurophysiology in the preclinical departments indicted asynchrony and redundancy in topics that may reduce the learning and reduce teaching time efficiency of the neuroscience courses. It is suggested that learning experiences of medical students should be routinely monitored and structured to ensure that the graduate doctor is able to understand and transfer learned experiences into clinical studies and practice. A horizontally integrated curriculum may be one way of raising students knowledge, attitude and skills in neuroscience courses as taught in the preclinical departments and is suggested.
\end{abstract}

Key word: Students, horizontal integration, learning experiences, curriculum.

\section{Introduction}

At the Nnamdi Azikiwe University medical school teaching is generally by the traditional method. The three preclinical departments of anatomy, physiology and biochemistry teach neuroscience courses during the second and third years of a six-year medical programme. These separate courses span a total of 68 hours of a tight timetable. Students perform comparatively poorly in the neuroscience courses of these departments. Teaching and learning at the basic sciences level poses significant challenges of correlation, imagination and transfer of learned experiences (APS refresher course report, 2001; Cross PK, 1987; Barrows et al, 2001; and Genneth et al, 1992). It is probably true that neurophysiology is hardly taught with many active learning experiences or examples (Lake, 1999) or the students are not able to associate the concepts to previous knowledge or experiences on which the teacher can build upon (Michael, 2001; Walters, 1999). It is however certain that any learning experience that is conditionalized effectively supports understanding and transfer to other contexts for use beyond the ability to recall facts and figures (Nshaho, 2005; Committee on developments in the science of learning, 2004). The ultimate goal of medical education is to enable the graduate to transfer sets of what has been learnt to wider contexts and to the contexts of challenges of medical practice (Anyaehie et al, 2007). An analysis of the neuroscience curriculum of three departments showed that the various neuroscience topics were taught at different times/semesters during the twoyear preclinical training, which probably makes the learning more challenging.

Basic science teaching is fraught with special difficulties ranging from sustaining interest and clinical correlation (Nwobodo, 2005). It is expected that institutions should continuously monitor what works and what does not work with their curriculum and adapt as required (Committee on developments in the science of learning, 2004). The medical learning objective project organized by the American Physiological Society and Association of Chairs of Departments of Physiology in 1998 constructed 682 individual physiology-learning objectives.(Available www.the.aps.org/education/medphys obj/medcor.com) and part of the recommendation is the introduction of new ways of teaching 
E. Nwobodo et al

physiology to enable students transfer the learning. This study attempted to justify the current curriculum of neurophysiology in this medical school in terms of content and its learning objectives. This included ability to transfer knowledge, level of understanding reflected in the academic performances of the learners. These variables determine the success or otherwise of a curriculum and should provide the stimulus for a review of curriculum and teaching practices. The goal of the project is to proffer suggestions in order to improve the understanding of neuroscience courses by preclinical students and ultimately their clinical application of same. The specific objectives were to improve students' performance in neuroscience courses, improve the competence of clinical students in neurological postings, improve the teachers' competence and satisfaction in the teaching of neuroscience and finally to improve the quality of patient care.

\section{Methods}

Subjects and location

This study was approved by the College Ethics Committee of the Nnamdi Azikiwe University Medical School. The study recruited medical students and their teachers and a batch of graduands of a medical school in Nigeria. The informed consent of all respondents was obtained. The study comprised of a structured questionnaire surveys interviews and review of academic records.

\section{Students Performances}

The performances of students in neurophysiology, cardiovascular and endocrinology at the second professional ( $\left.2^{\text {nd }} \mathrm{MBBS}\right)$ physiology examination were compared over a three-year period. Three hundred randomly selected essay scripts of 2nd MBBS candidates covering three years were analysed. The consecutive scores of the candidates were summed and the mean score obtained sum of scores/100. The data was subsequently subjected to students' t-test for variance with significance set at a P level of 0.05 . Students and staff perceptions and prescriptions 100 students who had completed the professional examination and 10 teachers were surveyed. Their perceptions of the learning and teaching of neurophysiology courses were ascertained using a structured questionnaire in which the respondents were specifically requested to give their perceptions of their learning or teaching experiences of neurophysiology or neuroscience or neurology courses (open-ended) and offer prescriptions on how their learning or teaching experiences may improved upon. All surveys were administered in strict confidence and with the informed consent of all respondents.

\section{Exit survey of graduating doctors}

An exit survey of graduands of the medical school was taken $(n=50)$. The graduands were requested to freely list their future career options in medicine. The purpose of this survey was to ascertain if neurology featured in the career selection options of the graduands. The respondents were further requested to rate their knowledge and appreciation level of neurophysiology/neurosciences on a 5 point Licker scale ranging from excellent to very poor.

\section{Reviewing the curriculum}

A study group consisting of teachers of not less than 5 year teaching experience at the MBBS level in neurophysiology, neuroanatomy and neurochemistry or neurology initially from three departments of one medical school and later from three other medical schools analysed the curricular content of neuroscience courses as taught including timelines and sequence of topics for the three disciplines.

\section{Results}

\section{Students Performances}

The students' performance in physiology essay questions over a three-year period was significantly lower in neurophysiology than in two other areas of Physiology namely cardiovascular physiology and endocrinology at $40 \%$ vs. $59 \%$ vs. $55 \%$ respectively. The results are summarized in Table I. In effect, the average student taking the $2^{\text {nd }}$ MBBS examination failed the neurophysiology essay component of the physiology examination over a three-year period.

Table I: Comparative performance of students in different areas of Physiology $(n=300)$

\begin{tabular}{llll}
\hline $\begin{array}{l}\text { Scores } \\
\text { statistics }\end{array}$ & Areas of Physiology & \\
& & & \\
& Neurophysiology & CVS & Endocrinology \\
\hline Range (\%) & $30-52^{*}$ & $46-71$ & $47-66$ \\
$\begin{array}{l}\text { Performance: } \\
<50 \%\end{array}$ & $242(80.7 \%)^{*}$ & 96 & $102(34 \%)$ \\
$\geq 50 \%$ & $58(19.3 \%)^{*}$ & $(32 \%)$ & $198(66 \%)$ \\
& & $\begin{array}{l}204 \\
(68 \%)\end{array}$ & \\
$\begin{array}{l}\text { Average }(\%) \\
\text { Mean } \\
( \pm \text { SEM })\end{array}$ & $40(6.5) *$ & 59 & $55(5.0)$ \\
& & $(4.2)$ & \\
\hline
\end{tabular}

* = significant at $\mathrm{P} \leq 0.05 ; \mathrm{CVS}=$ cardiovascular system 
Perception of neurophysiology, curricular reform

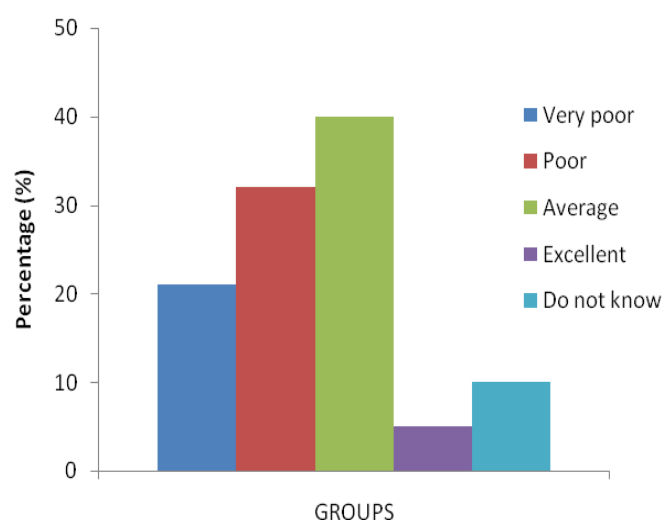

Fig. 1: Self-rated knowledge level of neurophysiology by Graduants

Exit survey

$50 \%$ of the graduating class respondents self-rated their performance in neurophysiology as either poor or very poor (Fig I). None of the graduands identified neurology or any neuroscience-based specialty as a possible career option. This obviously has implications in their ability to follow and apply the neuroscience knowledge in training and practice.

Students and staff perceptions and prescriptions: The students' perception of this area of physiology included the following

- Topic is uninteresting

- Teachers need to teach topic more clearly

- EXAMPLES are not given...

- Topic is at conflict with different teachers

- Crash programme of teaching

- Abstract concepts

In addition, the students' respondents made the following prescription for neurophysiology.

- $\quad$ Scrap the subject area (4\%)

- Devote more time $(60 \%)$

- Give more (real life) examples (25\%)

- $\quad$ Make lectures more interactive (15\%) (Fig III)

The prescription of the academic staff indicated the need to harmonize the teaching, allocate more teaching time to neuroscience and to recruit more staff.

The study group analyzed the curricular content with a view to developing a curriculum that will horizontally integrate the topics and reduce redundancy. This produced a horizontally integrated neuroscience curriculum comprising the contents of the preclinical departments that would require 60 hours excluding laboratory work time for implementation. In particular if the implementation were successful, horizontal integration of neuroscience course may amount to significant teaching time efficiency and synchronize learning and teaching of the subject areas.

\section{Reviewing the curriculum for neurophysiology}

The study group made some observations and recommendations. The group found that that various departments taught similar topics and these were taught at varied time in the training programme. The students were hard put to harmonize the information from the three departments when challenged. The group found the need to develop a horizontally integrated curriculum in which the departments taught a single neuroscience course and in which the topics are synchronized as ways of reducing redundancy and increasing teaching time efficiency. It found merit in a multidisciplinary approach to the teaching of neuroscience courses of the preclinical departments. Thus the first draft of a horizontally integrated curriculum of neuroscience was developed.

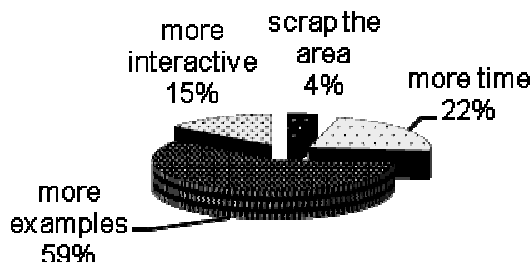

Fig. 2: Students' prescription on improvement of learning of neurophysiology

\section{Discussion}

It is difficult to innovate curricular change in a time constrained and strictly traditional curriculum setting but the perceptions of the students, their selfrating and performance in neurophysiology or areas of the curriculum are compelling reasons for a review of current teaching and learning practices. The poor performances of students at high stakes examination over a three year period (Table I) in neurophysiology relative to other areas is indicative of issues in the learning and teaching of that area. The perception of the students of this area is largely negative, $4 \%$ called for a scraping of the area while over $50 \%$ requested the teachers to use more examples (fig 1I). This indicates that the understanding of the area was weak for most of the surveyed students.

The graduating class of doctors reflected the persistence of observed negative perceptions of their peers in training. Over 50\% rated self as having a poor or very poor knowledge of neurophysiology. Indeed, none of the respondents selected any neuroscience-based specialty as a possible career option. The implication of this in their transfer of the expected neurophysiology 
E. Nwobodo et al

knowledge in their practice is obvious (Fig I). They are unable to transfer the knowledge as was anticipated by the curriculum. This would mean a failing in the curricular objective.

The prescription of the academic staff indicated the need to harmonize teaching, allocate more teaching time to neuroscience and to recruit more staff. With respect to the prescription for more teaching time and for more staff, there is no indication that other areas enjoyed more time or more staff teaching staff. Indeed, the teaching time for neurophysiology is proportionately higher than other areas of physiology at about 70 hours. There could be differences in experience levels or areas of specialization of the academic staff in a department but it is common knowledge that content teachers for neurophysiology are very few in the medical schools in Nigeria. Staff development thus is an important initial step for a better teaching and appreciation of neurosciences. However, the thrust of this report is the need to review the teaching and learning strategies for neurophysiology in response to established poor performances and negative perceptions of the learners in a medical school.

Curricular change, together with a carefully built students feedback, is essential for successful innovative curricular changes (Cunningham et al, 2001). A limited implementation of an integrated curriculum provides a learning opportunity. The logical next step from horizontal integration would consist of a vertical integration in which clinical contents are carefully built in to the curriculum to provide a continuum.

\section{Conclusion}

This is a call for integration of the teaching and learning of the neuroscience courses of the basic medical science. We report a significant poor performance and perception of the learning by students. We report a lack of future interests in the current traditional methods of teaching of neurophysiology at the Nnamdi Azikiwe University. It would be interesting to ascertain if this was a trend across the medical schools in Nigeria or an isolated case of teaching and learning. Undocumented experiences however indicate that medical students in Nigerian medical schools are seemingly uncomfortable with the neuroscience components of the basic training.

There are issues about assessments of integrated curriculum particularly at the professional examinations of the $2^{\text {nd }}$ MBBS. It is indeed helpful to institutionalize students' feedback processes in universities where they currently do not exist.

The curriculum under reference remains unimplemented and unapproved. It would be interesting to share the experiences with other medical schools under the same settings.

\section{Acknowledgements}

The authors wish to thank the ECFMG-

FAIMER Institute for sponsoring this project and the Nnamdi Azikiwe University for the support. To all respondents, we extend our gratitude for their time and thoughts.

\section{References}

Anyaehie U.S.B., Nwobodo Ed. and Njoku C.J (2007). Comparative evaluation of active learning and the traditional lectures in physiology: A case study of 200 level medical laboratory students of Imo State University, Owerri. Niger. J. Physiol. Sci. 22 (1-2): 117121.

APS Refresher course Report (2001). Adv. Physiol. Educ. 25(3): 211-249.

Barrows H.S, William R.G and Mary R.H (2001). A comparative performance based assessment of $4^{\text {th }}$ year students' clinical skills. J Med Educ 62: 805-807.

Committee on Developments in the Science of Learning (2004). How people learn (expanded edition). National Academy Press, Washington D.C.

Cross P.K (1987). Teaching for learning. Am. Assoc Higher Educ. Bull. 39:3-7.

Cunningham J.T, Freeman R.H and Hosokawa M.C (2001). Integration of neuroscience and endocrinology in hybrid PBL curriculum. $A d v$. Physiol. Educ. 25(3): 233-240.

Genneth S, Caston D, Kindly B and Smith J (1992). Review of three decades of laboratory exercises in the preclinical curriculum at the Case Western Reserve University of Medicine. Acad. Med 67: 203-206.

Lake A.D (1999). Peer tutoring improves student performance in advanced physiology course. Adv. Physiol. Educ. 21(1): S86-S92.

Michael J. (2001): In pursuit of meaningful learning; The Claude Bernard distinguished lecture 2001. Adv. Physiol. Educ. 25 (1-4); 145158.

Nshaho J. (2005). Innovative strategies in teaching biomedical sciences to health sciences. Niger. J. Physiol. Sci. 20(1-2): 8-10.

Nwobodo Ed. (2005). Paper presented at a workshop on curriculum development at the College of Medicine, University of Nigeria, Enugu campus, Nigeria

Walters M.R (1999). Case stimulated learning within endocrine physiology lectures: An approach applicable to other disciplines. Adv. Physiol. Educ.. 21(1); S74-S78. 